\title{
Clinical effects of natalizumab on multiple sclerosis appear early in treatment course
}

\author{
Ludwig Kappos • Paul W. O'Connor • Christopher H. Polman • \\ Patrick Vermersch • Heinz Wiendl • Amy Pace • \\ Annie Zhang $\cdot$ Christophe Hotermans
}

Received: 26 August 2012/Revised: 21 November 2012/Accepted: 15 December 2012/Published online: 5 January 2013

(C) The Author(s) 2012. This article is published with open access at Springerlink.com

\begin{abstract}
In clinical practice natalizumab is typically used in patients who have experienced breakthrough disease during treatment with interferon beta (IFN $\beta$ ) or glatiramer acetate. In these patients it is important to reduce disease activity as quickly as possible. In a phase II study, differences between natalizumab and placebo in MRI outcomes reflecting inflammatory activity were evident after the first infusion and maintained through a 6-month period, suggesting a rapid onset of natalizumab treatment effects. To explore how soon after natalizumab initiation clinical effects become apparent, annualized relapse rates per 3-month period and time to first relapse were analyzed
\end{abstract}

L. Kappos ( $\square)$

Departments of Neurology and Biomedicine,

University Hospital Basel, Petersgraben 4, Basel, Switzerland

e-mail: 1kappos@uhbs.ch

P. W. O'Connor

MS Clinic, St. Michael's Hospital, 3 Suther Wing D. Room

3007, 30 Bond Street, Toronto, ON, Canada

C. H. Polman

VU Medical Centre, PO Box 7057, 1007 MB Amsterdam,

The Netherlands

P. Vermersch

Department of Neurology, Clinique neurologique, Hôpital Roger Salengro, University of Lille Nord de France, CHU de Lille, Rue Emile Laine, 59037 Lille Cedex, France

H. Wiendl

Department of Neurology-Inflammatory Diseases of the Nervous System and Neurooncology, Neurology Clinic, University of Münster, Domagkstrasse 13, Munster, Germany

A. Pace $\cdot$ A. Zhang $\cdot$ C. Hotermans

Biogen Idec Inc., 133 Boston Post Road,

Weston, MA 02493, USA in the phase III AFFIRM study (natalizumab vs. placebo) and in the multinational Tysabri ${ }^{\circledR}$ Observational Program (TOP). In AFFIRM, natalizumab reduced the annualized relapse rate within 3 months of treatment initiation compared with placebo in the overall population $(0.30$ vs. 0.71 ; $p<0.0001)$ and in patients with highly active disease ( 0.30 vs. $0.94 ; p=0.0039)$. The low annualized relapse rate was maintained throughout the 2-year study period, and the risk of relapse in AFFIRM patients treated with natalizumab was reduced [hazard ratio against placebo 0.42 (95\% CI 0.34-0.52); $p<0.0001]$. Rapid reductions in annualized relapse rate also occurred in TOP (baseline 1.99 vs. $0-3$ months $0.26 ; p<0.0001$ ). Natalizumab resulted in rapid, sustained reductions in disease activity in both AFFIRM and in clinical practice. This decrease in disease activity occurred within the first 3 months of treatment even in patients with more active disease.

Keywords Multiple sclerosis - Natalizumab - Relapse · Disease activity $\cdot$ Disease-modifying therapy

Annualized relapse rate

\section{Introduction}

For patients with multiple sclerosis (MS), rapid control of disease activity is an important goal of therapy [1]. When clinical exacerbations are frequent and/or levels of radiologically apparent disease activity are high, effective treatment is especially crucial because the inflammation associated with active disease may lead not only to demyelination but also to potentially irreversible neuronal damage [2-6]. Disease-modifying therapies (DMTs) for the treatment of MS have been shown to reduce relapse rates and disability progression in pivotal studies over 
1-2 years [7-11]. Clinical effects occurring earlier than 1 year after initiation of therapy have not yet been well studied. Some studies, however, have shown significant benefits on annualized relapse rates and/or the number of gadolinium-enhancing lesions with DMTs versus placebo at 6 months, suggesting that the clinical effects of therapy could be detectable at earlier time points as well [12-14].

Natalizumab $\left(\right.$ Tysabri $^{\circledR}$, Biogen Idec, Weston, MA, and Elan Pharmaceuticals, Inc., San Francisco, CA) is a recombinant humanized monoclonal antibody that inhibits binding of the $\alpha 4$ subunit of the $\alpha 4 \beta 1$ and $\alpha 4 \beta 7$ integrins to their endothelial receptors and prevents trafficking of mononuclear leukocytes across the vascular endothelium of the central nervous system (CNS) $[15,16]$. In its pivotal monotherapy trial (AFFIRM), natalizumab showed efficacy at 1 and 2 years in treatment-naïve patients with relapsing forms of MS [15]. Analysis of 2-year data from AFFIRM revealed that natalizumab was also effective in the subgroup of patients with highly active disease, defined as having $\geq 2$ relapses in the year before study entry and $\geq 1$ gadolinium-enhancing lesion at study entry [17]. In additional studies, natalizumab was effective as a second-line therapy in patients with insufficient response to other DMTs [18-22].

Results from the phase II study suggest that natalizumab may reduce disease activity shortly after treatment initiation. At 1 month, the mean number of new gadolinium-enhancing lesions had already diverged between natalizumab- and placebo-treated patients, and the difference was maintained over time. At 6 months, there was an overall 89-93\% reduction of new gadolinium-enhancing lesions with natalizumab compared with placebo, as well as a significant reduction in the number of relapses [14].

To further explore when the effects of natalizumab on clinical relapses occur and whether the time course of clinical effects is dependent on the degree of baseline disease activity, we conducted post hoc analyses of data from AFFIRM. Because clinical practice likely has greater variability in patient characteristics compared with clinical trials, data from the clinical practice-based TYSABRI Observational Program (TOP) were also analyzed [23].

\section{Materials and methods}

\section{Study design—AFFIRM}

AFFIRM was a randomized, double-blind, placebocontrolled, phase III clinical study, in which 942 patients received natalizumab $300 \mathrm{mg}$ or placebo $(2: 1)$ by intravenous (i.v.) infusion once every 4 weeks for up to 116 weeks [15]. Relapses were defined as new or recurrent neurologic symptoms not associated with fever or infection that lasted $\geq 24 \mathrm{~h}$ and were accompanied by new neurologic signs found by the examining neurologist. Post hoc subgroup analyses of data from AFFIRM defined highly active disease as $\geq 2$ relapses in the year before study entry and $\geq 1$ gadoliniumenhancing lesion on T1-weighted magnetic resonance imaging (MRI) at study entry [17].

\section{Study design-TOP}

Tysabri ${ }^{\circledR}$ Observational Program is an ongoing 10-year, open-label, multinational, multicenter, prospective observational study evaluating the long-term safety and efficacy of natalizumab in the postmarketing clinical practice setting. As of December 1, 2011, 3,976 patients were enrolled [24].

In TOP, a clinical relapse is defined as new or recurrent neurological symptoms, not associated with fever, lasting for at least $24 \mathrm{~h}$, and followed by a period of 30 days of stability or improvement. New or recurrent neurological symptoms that occur less than 30 days following the onset of a protocol-defined relapse should be considered part of the same relapse.

Table 1 Baseline annualized relapse rates for patients in AFFIRM and TOP

\begin{tabular}{|c|c|c|c|c|c|}
\hline & \multicolumn{4}{|l|}{ AFFIRM } & \multirow{3}{*}{$\begin{array}{l}\text { TOP } \\
\text { Natalizumab } \\
\text { Overall }\end{array}$} \\
\hline & \multicolumn{2}{|l|}{ Natalizumab } & \multicolumn{2}{|l|}{ Placebo } & \\
\hline & Overall & HA & Overall & HA & \\
\hline Patients, $n$ & 627 & 148 & 315 & 61 & $3,963^{\mathrm{a}}$ \\
\hline \multicolumn{6}{|c|}{ Relapses during prior year, $n$} \\
\hline Mean \pm SD & $1.53 \pm 0.91$ & $2.45 \pm 1.19$ & $1.50 \pm 0.77$ & $2.28 \pm 0.55$ & $1.99 \pm 1.03$ \\
\hline $95 \% \mathrm{CI}$ & $1.46-1.60$ & $2.25-2.64$ & $1.42-1.59$ & $2.14-2.42$ & $1.96-2.03$ \\
\hline Median (range) & $1(0-12)$ & $2(2-12)$ & $1(0-5)$ & $2(2-4)$ & $2(0-10)$ \\
\hline
\end{tabular}

$H A$ highly active, defined as having $\geq 2$ relapses in the year before study entry and $\geq 1$ gadolinium-enhancing lesion at study entry

${ }^{a}$ Baseline relapse rates were not available for 13 patients in TOP 
AFFIRM and TOP were approved by the appropriate ethics committees and performed in accordance with the Declaration of Helsinki and Good Clinical Practice guidelines. All patients provided written informed consent.

Statistical analysis

Analyses were conducted for overall AFFIRM and TOP populations and for the subgroup of AFFIRM patients with highly active disease. Annualized relapse rates per 3-month interval were calculated as the total number of relapses divided by total person-years observed within the interval.
Point estimates, confidence intervals (CIs), and treatment effects (rate ratios) for each interval were estimated from a Poisson model with overdispersion. For TOP data, annualized relapse rates were estimated at each time point using a negative binomial model. Treatment effects on time to first relapse (in days) at a specific time point were assessed using hazard ratios (HR) estimated from a Cox proportional hazards model, adjusting for the number of relapses in the year before study entry. The cumulative probability of relapse was estimated using the Kaplan-Meier method, and $95 \%$ confidence bands were derived using the equal precision approach [25]. A log-rank test was used to (a)

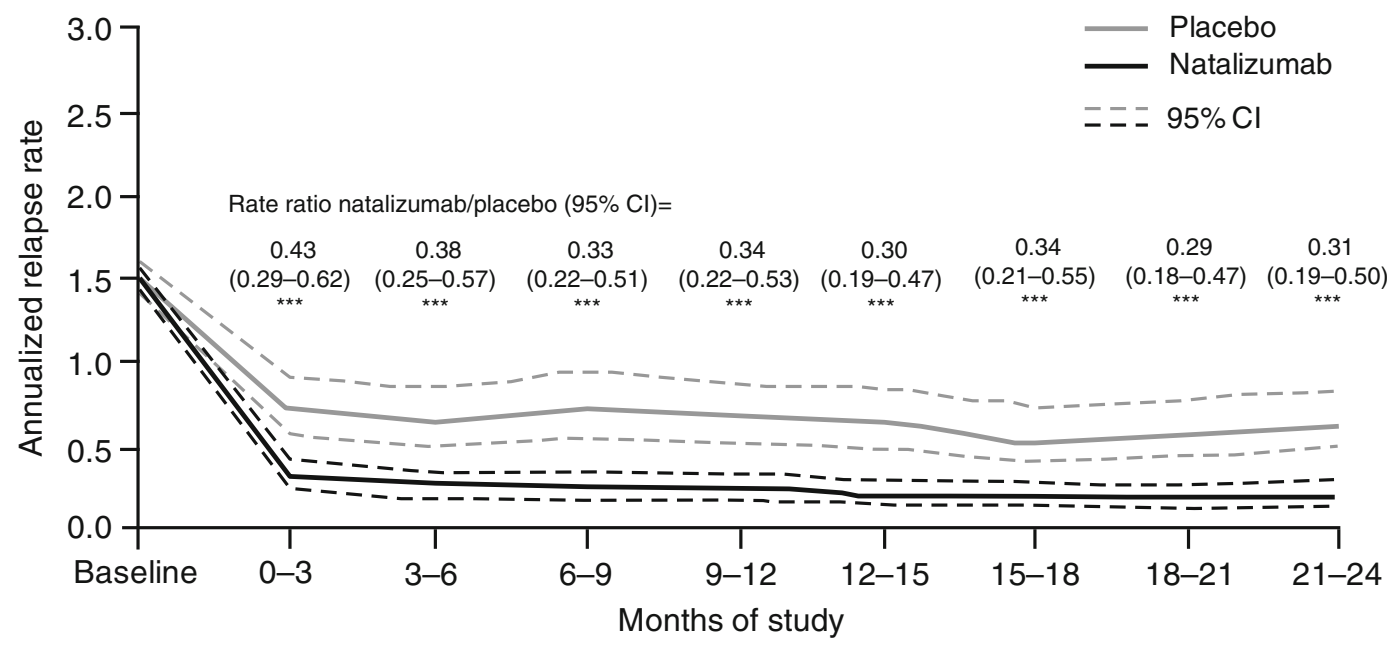

Number of patients at risk

$\begin{array}{lllllllll}\text { Placebo } & 315 & 315 & 308 & 307 & 300 & 297 & 294 & 292 \\ \text { Natalizumab } & 627 & 627 & 621 & 615 & 612 & 609 & 600 & 597\end{array}$

(b)

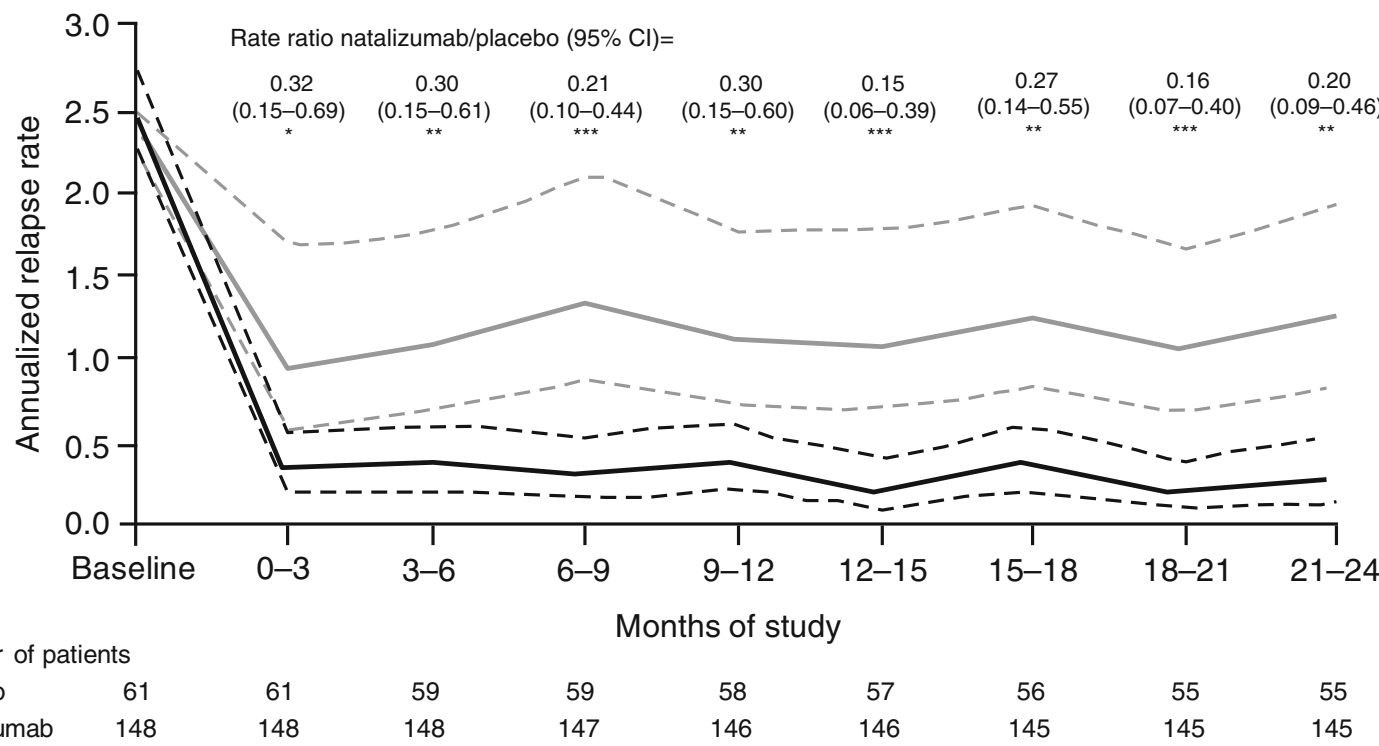

Fig. 1 Annualized relapse rate over time (calculated for each 3-month interval) in AFFIRM patients overall (a) and with highly active disease (b) is shown for placebo-treated (solid gray line) and natalizumab-treated (solid black line) patients; $95 \% \mathrm{CI}$ are indicated by dashed lines. Rate ratios of natalizumab/placebo (95\% CI) for each time period are indicated in the graphs. ${ }^{*} p<0.01$; $* * p 0.001$; $* * * p<0.0001$ 


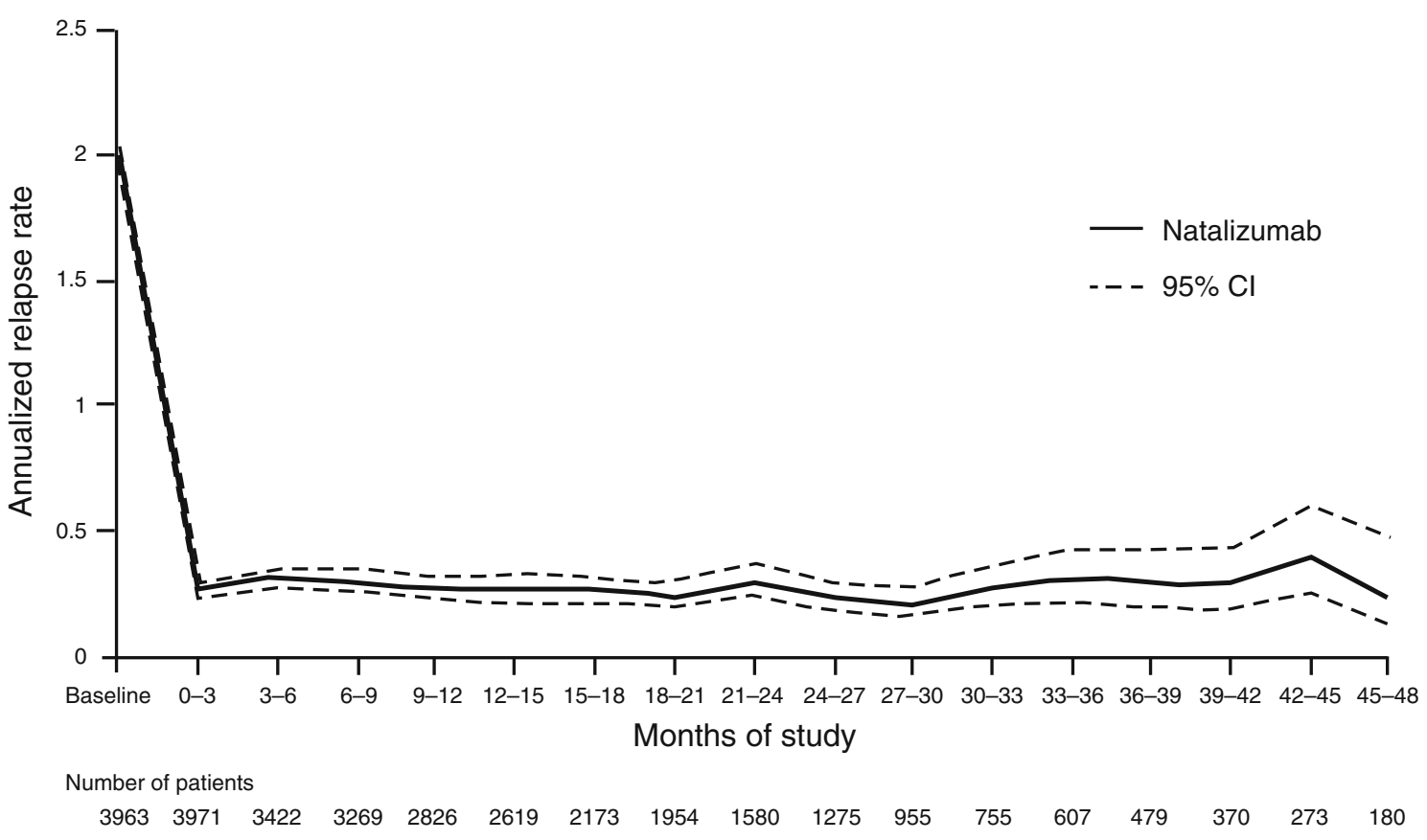

Fig. 2 Annualized relapse rate over time in TOP patients is shown as a solid line; $95 \%$ CIs are indicated by dashed lines. Five patients did not receive natalizumab and were excluded from post-baseline analyses

determine the first day a significant difference in the cumulative probability of relapse emerged between study groups.

\section{Results}

Baseline relapse rates

Relapse rates at baseline for patients in AFFIRM and TOP are shown in Table 1. Overall, the mean baseline relapse rate in AFFIRM was 1.5 relapses in the prior year. A total of 209 patients (148 natalizumab and 61 placebo) in AFFIRM met the criteria for highly active MS, with a mean relapse rate of 2.5 relapses in the year prior to study entry.

The median (range) disease duration prior to starting natalizumab was similar for the two studies: $5(0-34)$ years for AFFIRM and $7(0-44)$ years for TOP $[15,23]$. The majority $(90 \%)$ of TOP patients had used another DMT prior to starting natalizumab [23]. The mean relapse rate at baseline among TOP patients was approximately 2.0, similar to the rate in AFFIRM patients with highly active disease (Table 1).

\section{Annualized relapse rate}

In AFFIRM natalizumab monotherapy reduced annualized relapse rate already within the first 3 months of treatment compared with placebo overall $[0.30$ (95\% CI $0.23-0.40)$ vs. 0.71 (95\% CI $0.55-0.91) ; p<0.0001]$ and in patients with highly active disease [0.30 (95\% CI $0.17-0.53)$ vs. 0.94 (95 \% CI 0.55-1.63); $p=0.0039$ ]. This treatment effect was maintained throughout the 2-year controlled study period and was observed despite the fact that sizeable reductions from baseline annualized relapse rate occurred also in the placebo group (Fig. 1).

In TOP, annualized relapse rate was reduced from 1.99 (95\% CI 1.96-2.03) at baseline to $0.26(95 \% \mathrm{CI}$ $0.23-0.30 ; p<0.0001)$ after 3 months of natalizumab treatment and was maintained at that rate at 4 years (Fig. 2).

Time to first relapse

Kaplan-Meier curves estimating the cumulative probability of relapse over 2 years in AFFIRM patients overall and in those with highly active disease are shown in Fig. 3. A significant treatment effect comparing natalizumab versus placebo was observed at 8 weeks after initiating treatment (Table 2). A difference in the cumulative probability of relapse from baseline between the two groups was first observed at day 42 in patients overall, $5.4 \%$ for natalizumab and $9.3 \%$ for placebo (HR: $0.56,95 \%$ CI $0.34-0.93 ; p=0.0238$ ), and at day 45 in patients with highly active disease, $6.8 \%$ for natalizumab and $16.6 \%$ for placebo (HR: 0.35, $95 \%$ CI $0.14-0.87 ; p=0.0243$ ). The treatment effect was maintained at 2 years. Overall, natalizumab treatment reduced the risk of relapse by $58 \%$ over 2 years relative to placebo $(p<0.0001)$. In patients 

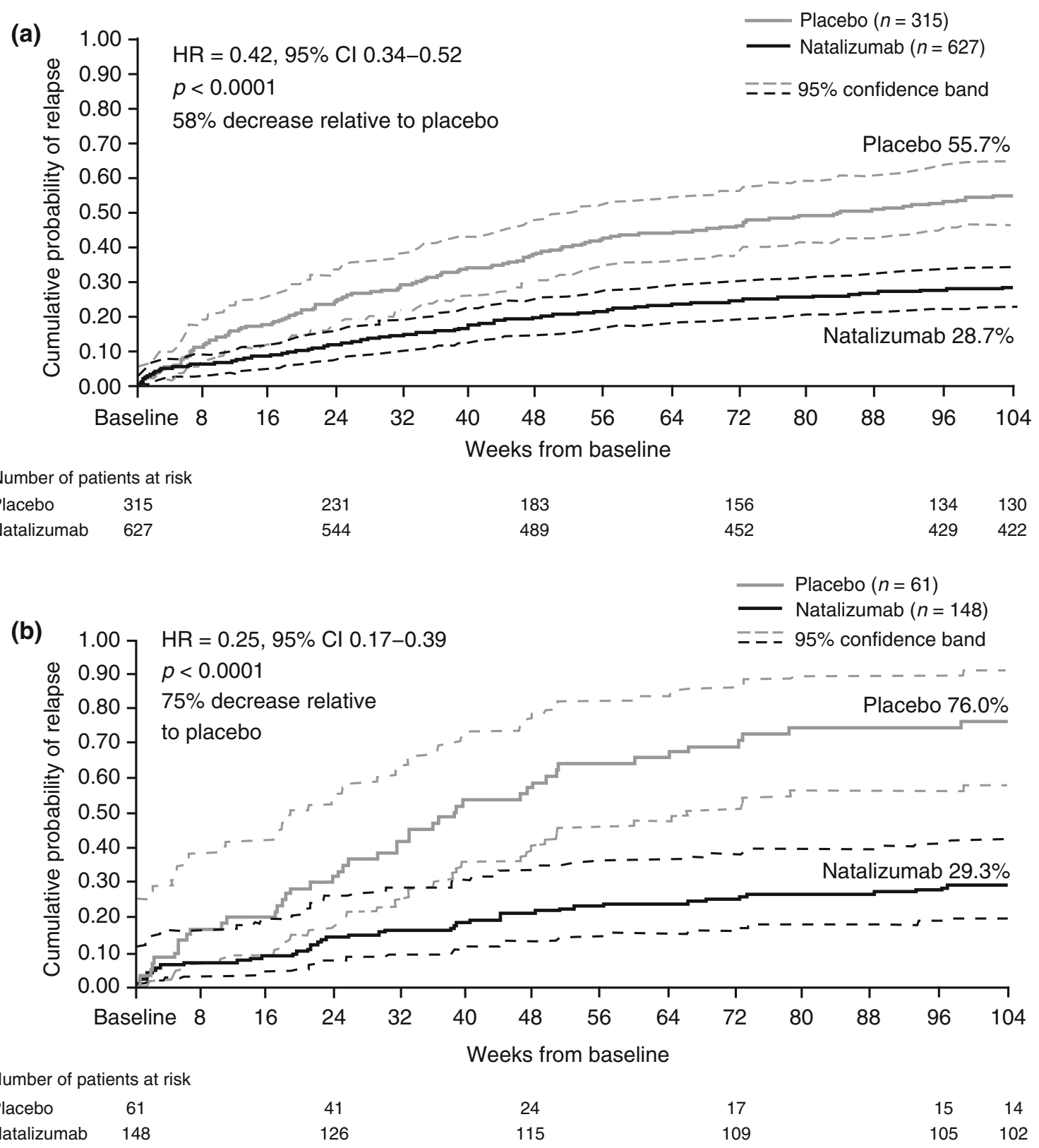

Fig. 3 Cumulative probability of relapse in AFFIRM patients overall (a) and with highly active disease (b) is shown for placebo-treated (gray line) and natalizumab-treated (black line) patients

with highly active disease, natalizumab reduced the risk of relapse by $75 \%$ over 2 years relative to placebo $(p<0.0001)$.

At 4,8 , and 12 weeks in TOP, patients treated with natalizumab had an estimated $2.4,4.0$, and $5.7 \%$ cumulative risk of relapse from baseline, respectively. At 2 years, the estimated risk was $32 \%$, similar to the risk in natalizumab-treated AFFIRM patients at 2 years. At 3 years in TOP, the cumulative risk of relapse was $42 \%$ (Fig. 4).

\section{Discussion}

In AFFIRM, natalizumab had a significant effect on annualized relapse rate within 3 months of initiating therapy, and reductions were sustained over the 2-year controlled study period. Combined with the MRI findings of the phase II study in which reductions in the mean number of new gadolinium-enhancing lesions in natalizumab-treated patients versus placebo were apparent after 1 month and remained reduced as long as treatment was continued 
[14], these data suggest that natalizumab reduces disease activity shortly after initiating treatment.

Natalizumab also had a significant effect on the cumulative probability of relapse over 2 years, with significant reductions being observed by 8 weeks after starting treatment. These rapid, sustained reductions in annualized relapse rate and risk of relapse with natalizumab treatment occurred regardless of baseline disease activity in the overall population and in the subset of patients with highly active disease.

Observations from a clinical practice setting (TOP) were similar to the clinical trial results but should be interpreted with caution owing to the lack of a reference group. Nevertheless, given the differences in patient demographics and disease characteristics between the clinical studies and TOP, these results suggest that the results from the
Table 2 Cumulative risk of relapse from baseline for patients in AFFIRM
$H A$ highly active, defined as having $\geq 2$ relapses in the year before study entry and $\geq 1$ gadolinium-enhancing lesion at study entry

Fig. 4 Cumulative probability of relapse in TOP patients is shown as a solid line; $95 \%$ confidence band is indicated by dashed lines. Five patients did not receive natalizumab and were excluded from postbaseline analyses

\begin{tabular}{|c|c|c|c|c|}
\hline & \multicolumn{2}{|l|}{ Overall } & \multicolumn{2}{|l|}{ HA } \\
\hline & Natalizumab & Placebo & Natalizumab & Placebo \\
\hline \multicolumn{5}{|c|}{ Cumulative risk of relapse at 4 weeks from baseline } \\
\hline Percentage & 4.6 & 4.8 & 6.1 & 8.3 \\
\hline $\mathrm{HR}(95 \% \mathrm{CI})$ & \multicolumn{2}{|c|}{$0.96(0.51-1.79)$} & \multicolumn{2}{|l|}{$0.72(0.24-2.16)$} \\
\hline$p$ value & \multicolumn{2}{|l|}{0.8893} & \multicolumn{2}{|l|}{0.5578} \\
\hline \multicolumn{5}{|c|}{ Cumulative risk of relapse at 8 weeks from baseline } \\
\hline Percentage & 5.7 & 12.2 & 6.8 & 16.6 \\
\hline $\mathrm{HR}(95 \% \mathrm{CI})$ & \multicolumn{2}{|c|}{$0.45(0.29-0.72)$} & \multicolumn{2}{|l|}{$0.35(0.14-0.87)$} \\
\hline$p$ value & \multicolumn{2}{|l|}{0.0007} & \multicolumn{2}{|l|}{0.0243} \\
\hline \multicolumn{5}{|c|}{ Cumulative risk of relapse at 12 weeks from baseline } \\
\hline Percentage & 7.2 & 16.7 & 7.4 & 20.0 \\
\hline $\mathrm{HR}(95 \% \mathrm{CI})$ & \multicolumn{2}{|c|}{$0.41(0.28-0.61)$} & \multicolumn{2}{|l|}{$0.33(0.14-0.76)$} \\
\hline$p$ value & \multicolumn{2}{|l|}{$<0.0001$} & \multicolumn{2}{|l|}{0.0090} \\
\hline \multicolumn{5}{|c|}{ Cumulative risk of relapse at 24 weeks from baseline } \\
\hline Percentage & 11.9 & 25.4 & 14.2 & 33.3 \\
\hline $\mathrm{HR}(95 \% \mathrm{CI})$ & \multicolumn{2}{|c|}{$0.43(0.31-0.59)$} & \multicolumn{2}{|l|}{$0.37(0.20-0.68)$} \\
\hline$p$ value & \multicolumn{2}{|l|}{$<0.0001$} & \multicolumn{2}{|l|}{0.0015} \\
\hline \multicolumn{5}{|c|}{ Cumulative risk of relapse at 48 weeks from baseline } \\
\hline Percentage & 20.0 & 39.2 & 21.7 & 58.9 \\
\hline $\mathrm{HR}(95 \% \mathrm{CI})$ & \multicolumn{2}{|c|}{$0.45(0.35-0.57)$} & \multicolumn{2}{|l|}{$0.28(0.17-0.45)$} \\
\hline$p$ value & \multicolumn{2}{|l|}{$<0.0001$} & \multicolumn{2}{|l|}{$<0.0001$} \\
\hline \multicolumn{5}{|c|}{ Cumulative risk of relapse at 104 weeks from baseline } \\
\hline Percentage & 28.7 & 55.7 & 29.3 & 76.0 \\
\hline $\mathrm{HR}(95 \% \mathrm{CI})$ & \multicolumn{2}{|c|}{$0.42(0.34-0.52)$} & \multicolumn{2}{|l|}{$0.25(0.17-0.39)$} \\
\hline$p$ value & \multicolumn{2}{|l|}{$<0.0001$} & \multicolumn{2}{|l|}{$<0.0001$} \\
\hline
\end{tabular}

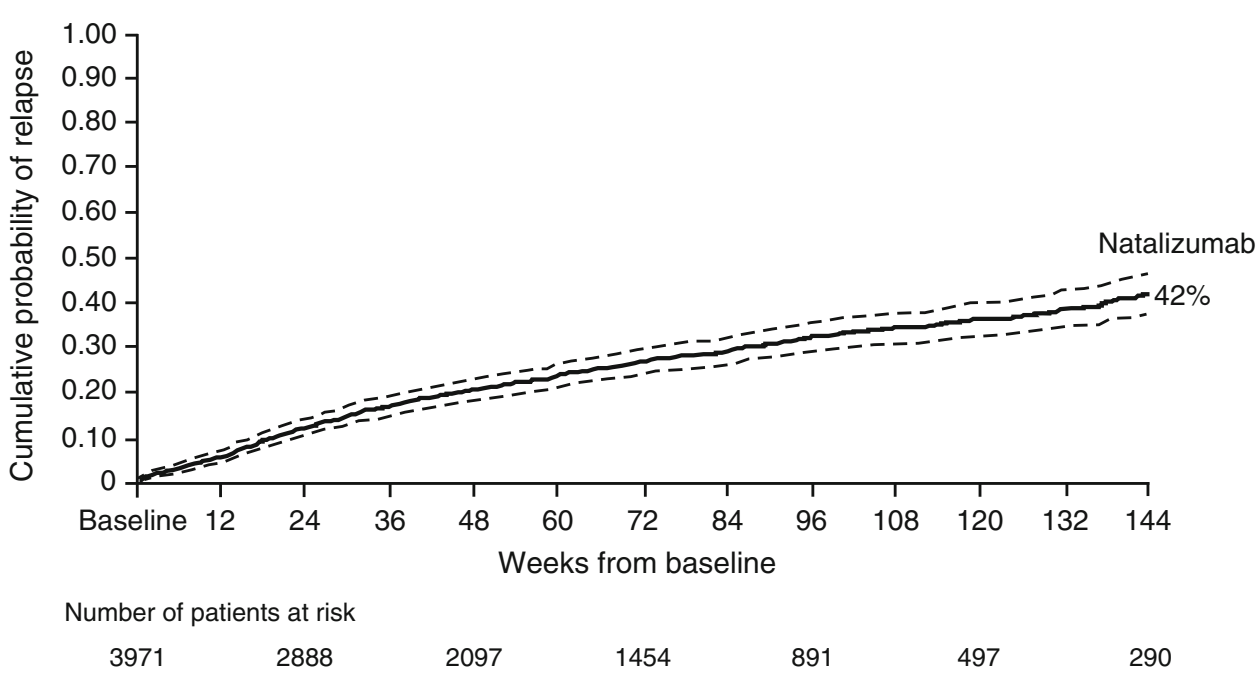


pivotal studies are applicable to those patients included in the current label of natalizumab. This is particularly remarkable regarding the potential utility of natalizumab for patients experiencing MS disease activity despite treatment with other DMTs to rapidly gain control of disease and help prevent further cumulative damage.

Our findings are consistent with those of numerous post-marketing studies that have observed significant improvements in annualized relapse rate, radiologic disease, ambulation, or disability progression in patients, including those with highly active disease, switching to natalizumab from other DMTs, although most assessments were performed at 1 year after initiating natalizumab [18, 19, 21, 22, 26-32]. The results of this analysis are also consistent with a separate AFFIRM analysis that showed an increased probability of sustained improvement in Extended Disability Status Scale (EDSS) scores with natalizumab compared with placebo emerging during the first 24 weeks of treatment [33].

Natalizumab's rapid effects and ability to control disease in patients with highly active MS may be best explained by the inhibition of leukocyte migration into brain tissue that prevents lesion formation and reduces inflammatory cell recruitment into existing lesions [34, 35]. In addition to preventing leukocyte entry into the CNS, there is evidence that natalizumab may dampen ongoing inflammation in the CNS by disrupting interactions between inflammatory leukocytes and extracellular matrix proteins such as fibronectin and osteopontin or by inducing apoptosis of activated $\mathrm{T}$ cells [36-38].

In summary, rapid onset of natalizumab clinical efficacy shortly after treatment initiation may provide both shortand long-term benefits.

Acknowledgments Medical writing assistance was provided by Britt Anderson, $\mathrm{PhD}$, and editorial support was provided by Mary Kacillas, both of Infusion Communications. Their work was funded by Biogen Idec Inc. and Elan Pharmaceuticals, Inc.

Conflicts of interest The University Hospital Basel as employer of Dr. Kappos has received and dedicated to research support fees for board membership, consultancy or speaking, or grants, in the last 3 years from Actelion, Advancell, Allozyne, Bayer, Bayhill, Biogen Idec, BioMarin, CSL Behring, Eli Lilly, European Union, GeNeuro, Genmab, Gianni Rubatto Foundation, Glenmark, Merck Serono, MediciNova, Mitsubishi Pharma, Novartis, Novartis Research Foundation, Novonordisk, Peptimmune, Roche, Roche Research Foundation, Sanofi-Aventis, Santhera, Swiss MS Society, Swiss National Research Foundation, Teva, UCB, and Wyeth. Dr. O'Connor has received research support and honoraria from Biogen Idec Inc. Dr. Polman has received compensation for activities from Actelion, Bayer Schering, Biogen Idec, GlaxoSmithKline, Merck Serono, MorphoSys AG, Novartis, Teva, UCB, and Roche as a consultant/ speaker; and research support from Bayer Schering, Biogen Idec, GlaxoSmithKline, Merck Serono, Novartis, Roche, Teva, and UCB. Dr. Vermersch has received honoraria and consulting fees from Almirall, Bayer, Biogen Idec, Merck Serono, Novartis, and Teva; and research support from Bayer, Biogen Idec, Merck Serono, and Novartis. Dr. Wiendl has received honoraria for lecturing, travel expenses for attending meetings from Bayer Health Care, Biogen Idec/Elan Corporation, Lilly, Lundbeck Merck Serono, Novartis, Sanofi Aventis, and TEVA Neuroscience; has served/serves as a consultant for Biogen Idec, Merck Serono, Novartis Pharma, Sanofi-Aventis; and receives research support from Bayer Schering Pharma, Biogen Idec/Elan Corporation, Merck Serono, Novartis, Novo Nordisk and Sanofi-Aventis. Drs. Pace, Zhang, and Hotermans are employees of Biogen Idec.

Ethical standards Both studies, AFFIRM and TOP have been conducted after approval of the respective local Institutional Review Boards.

Open Access This article is distributed under the terms of the Creative Commons Attribution License which permits any use, distribution, and reproduction in any medium, provided the original author(s) and the source are credited.

\section{References}

1. Caon C (2009) Maximising therapeutic outcomes in patients failing on current therapy. J Neurol Sci 277(Suppl 1):S33-S36

2. Boster A, Edan G, Frohman E, Javed A, Stuve O, Tselis A, Weiner H, Weinstock-Guttman B, Khan O, Multiple Sclerosis Clinical Research Center DoNWSUSoM (2008) Intense immunosuppression in patients with rapidly worsening multiple sclerosis: treatment guidelines for the clinician. Lancet Neurol $7(2): 173-183$

3. Comi G (2009) Shifting the paradigm toward earlier treatment of multiple sclerosis with interferon beta. Clin Ther 31(6):1142-1157

4. Coyle PK, Hartung HP (2002) Use of interferon beta in multiple sclerosis: rationale for early treatment and evidence for dose- and frequency-dependent effects on clinical response. Mult Scler 8(1):2-9

5. Tintore M (2008) Rationale for early intervention with immunomodulatory treatments. J Neurol 255(Suppl 1):37-43

6. Trapp BD, Peterson J, Ransohoff RM, Rudick R, Mörk S, Bö L (1998) Axonal transection in the lesions of multiple sclerosis. N Engl J Med 338(5):278-285

7. IFNB Multiple Sclerosis Study Group (1993) Interferon beta-1b is effective in relapsing-remitting multiple sclerosis. I. Clinical results of a multicenter, randomized, double-blind, placebo-controlled trial. Neurology 43(4):655-661

8. Jacobs LD, Cookfair DL, Rudick RA, Herndon RM, Richert JR, Salazar AM, Fischer JS, Goodkin DE, Granger CV, Simon JH, Alam JJ, Bartoszak DM, Bourdette DN, Braiman J, Brownscheidle CM, Coats ME, Cohan SL, Dougherty DS, Kinkel RP, Mass MK, Munschauer FE, III, Priore RL, Pullicino PM, Scherokman BJ, Whitham RH (1996) Intramuscular interferon beta-1a for disease progression in relapsing multiple sclerosis. The Multiple Sclerosis Collaborative Research Group (MSCRG). Ann Neurol 39(3):285-294

9. Johnson KP, Brooks BR, Cohen JA, Ford CC, Goldstein J, Lisak RP, Myers LW, Panitch HS, Rose JW, Schiffer RB (1995) Copolymer 1 reduces relapse rate and improves disability in relapsing-remitting multiple sclerosis: results of a phase III multicenter, double-blind placebo-controlled trial. The Copolymer 1 Multiple Sclerosis Study Group. Neurology 45(7):1268-1276

10. Kappos L, Radue EW, O'Connor P, Polman C, Hohlfeld R, Calabresi P, Selmaj K, Agoropoulou C, Leyk M, Zhang-Auberson L, Burtin P (2010) A placebo-controlled trial of oral fingolimod in relapsing multiple sclerosis. N Engl J Med 362(5):387-401

11. PRISMS (Prevention of Relapses and Disability by Interferon b-1a Subcutaneously in Multiple Sclerosis) Study Group (1998) Randomised double-blind placebo-controlled study of interferon 
beta-1a in relapsing/remitting multiple sclerosis. Lancet 352(9139):1498-1504

12. Comi G, Filippi M, Wolinsky JS (2001) European/Canadian multicenter, double-blind, randomized, placebo-controlled study of the effects of glatiramer acetate on magnetic resonance imaging-measured disease activity and burden in patients with relapsing multiple sclerosis. European/Canadian Glatiramer Acetate Study Group. Ann Neurol 49(3):290-297

13. Kappos L, Antel J, Comi G, Montalban X, O'Connor P, Polman CH, Haas T, Korn AA, Karlsson G, Radue EW (2006) Oral fingolimod (FTY720) for relapsing multiple sclerosis. N Engl J Med 355(11):1124-1140

14. Miller DH, Khan OA, Sheremata WA, Blumhardt LD, Rice GP, Libonati MA, Willmer-Hulme AJ, Dalton CM, Miszkiel KA, O'Connor PW, International Natalizumab Multiple Sclerosis Trial Group (2003) A controlled trial of natalizumab for relapsing multiple sclerosis. N Engl J Med 348(1):15-23

15. Polman CH, O'Connor PW, Havrdová E, Hutchinson M, Kappos L, Miller DH, Phillips JT, Lublin FD, Giovannoni G, Wajgt A, Toal M, Lynn F, Panzara MA, Sandrock AW, AFFIRM Investigators (2006) A randomized, placebo-controlled trial of natalizumab for relapsing multiple sclerosis. N Engl J Med 354(9):899-910

16. Yednock TA, Cannon C, Fritz LC, Sanchez-Madrid F, Steinman L, Karin N (1992) Prevention of experimental autoimmune encephalomyelitis by antibodies against alpha 4 beta 1 integrin. Nature 356(6364):63-66

17. Hutchinson M, Kappos L, Calabresi PA, Confavreux C, Giovannoni G, Galetta SL, Havrdova E, Lublin FD, Miller DH, O'Connor PW, Phillips JT, Polman CH, Radue EW, Rudick RA, Stuart WH, Wajgt A, Weinstock-Guttman B, Wynn DR, Lynn F, Panzara MA, AFFIRM and SENTINEL Investigators (2009) The efficacy of natalizumab in patients with relapsing multiple sclerosis: subgroup analyses of AFFIRM and SENTINEL. J Neurol 256(3):405-415

18. Belachew S, Phan-Ba R, Bartholomé E, Delvaux V, Hansen I, Calay P, Hafsi KE, Moonen G, Tshibanda L, Vokaer M (2011) Natalizumab induces a rapid improvement of disability status and ambulation after failure of previous therapy in relapsing-remitting multiple sclerosis. Eur J Neurol 18(2):240-245

19. Krysko KM, O'Connor PW (2011) The Toronto observational study of natalizumab in multiple sclerosis. Can J Neurol Sci 38(3):422-428

20. Outteryck O, Ongagna JC, Zephir H, Fleury MC, Lacour A, Blanc F, Vermersch P, de Sèze J (2010) Demographic and clinic characteristics of French patients treated with natalizumab in clinical practice. J Neurol 257(2):207-211

21. Putzki N, Yaldizli O, Maurer M, Cursiefen S, Kuckert S, Klawe C, Maschke M, Tettenborn B, Limmroth V (2010) Efficacy of natalizumab in second line therapy of relapsing-remitting multiple sclerosis: results from a multi-center study in German speaking countries. Eur J Neurol 17(1):31-37

22. Sangalli F, Moiola L, Bucello S, Annovazzi P, Rizzo A, Radaelli M, Vitello G, Grimaldi LM, Ghezzi A, Martinelli V, Comi G (2011) Efficacy and tolerability of natalizumab in relapsingremitting multiple sclerosis patients: a post-marketing observational study. Neurol Sci 31(Suppl 3):299-302

23. Pellegrini F, Belachew S, Butzkueven H, Trojano M, Wiendl H, Zhang A, Hotermans C (2012) Long-term safety and efficacy of natalizumab and assessment of 2-year freedom from clinical disease activity in patients with multiple sclerosis in the TYSABRI $^{\circledR}$ Observational Programme. Presented at: 28th Congress of European Committee for Treatment \& Research in Multiple Sclerosis, October 10-13, 2012. Lyon, France. P519. Mult Scler 18(S4):220-221. P519

24. Kappos L, Belachew S, Butzkueven H, Pellegrini F, Trojano M, Wiendl H, Zhang A, Hotermans C (2012) Long-term safety and efficacy and association between baseline treatment history and postbaseline relapses in multiple sclerosis patients treated with natalizumab in the TYSABRI ${ }^{\circledR}$ Observational Program (TOP). Presented at: 64th Annual Meeting of the American Academy of Neurology, April 21-28, 2012. New Orleans. P04.133

25. Nair VN (1984) Confidence bands for survival functions with censored data: a comparative study. Technometrics 26(3):265-275

26. Fernández O, Oreja-Guevara C, Arroyo R, Izquierdo G, Perez JL, Montalban X (2012) Natalizumab treatment of multiple sclerosis in Spain: results of an extensive observational study. J Neurol 259(9):1814-1823

27. Holmén C, Piehl F, Hillert J, Fogdell-Hahn A, Lundkvist M, Karlberg E, Nilsson P, Dahle C, Feltelius N, Svenningsson A, Lycke J, Olsson T (2011) A Swedish national post-marketing surveillance study of natalizumab treatment in multiple sclerosis. Mult Scler 17(6):708-719

28. Kallweit U, Jelcic I, Braun N, Fischer H, Zorner B, Schreiner B, Sokolov AA, Martin R, Weller M, Linnebank M (2012) Sustained efficacy of natalizumab in the treatment of relapsing-remitting multiple sclerosis independent of disease activity and disability at baseline: real-life data from a Swiss cohort. Clin Neuropharmacol 35(2):77-80

29. Lanzillo R, Bonavita S, Quarantelli M, Vacca G, Lus G, Amato L, Carotenuto A, Tedeschi G, Orefice G, Brescia M, V (2012) Natalizumab is effective in multiple sclerosis patients switching from other disease modifying therapies in clinical practice. Neurol Sci. doi:10.1007/s10072-012-1088-8

30. Oturai AB, Koch-Henriksen N, Petersen T, Jensen PE, Sellebjerg F, Sorensen PS (2009) Efficacy of natalizumab in multiple sclerosis patients with high disease activity: a Danish nationwide study. Eur J Neurol 16(3):420-423

31. Prosperini L, Borriello G, Fubelli F, Marinelli F, Pozzilli C (2011) Natalizumab treatment in multiple sclerosis: the experience of S. Andrea MS Centre in Rome. Neurol Sci 31 (Suppl 3): 303-307

32. Putzki N, Yaldizli O, Bühler R, Schwegler G, Curtius D, Tettenborn B (2010) Natalizumab reduces clinical and MRI activity in multiple sclerosis patients with high disease activity: results from a multicenter study in Switzerland. Eur Neurol 63(2):101-106

33. Phillips JT, Giovannoni G, Lublin FD, O'Connor PW, Polman CH, Willoughby E, Aschenbach W, Pace A, Hyde R, Munschauer FE (2011) Sustained improvement in Expanded Disability Status Scale as a new efficacy measure of neurological change in multiple sclerosis: treatment effects with natalizumab in patients with relapsing multiple sclerosis. Mult Scler 17(8):970-979

34. Rudick RA, Sandrock A (2004) Natalizumab: alpha 4-integrin antagonist selective adhesion molecule inhibitors for MS. Expert Rev Neurother 4(4):571-580

35. Tubridy N, Behan PO, Capildeo R, Chaudhuri A, Forbes R, Hawkins CP, Hughes RA, Palace J, Sharrack B, Swingler R, Young C, Moseley IF, MacManus DG, Donoghue S, Miller DH (1999) The effect of anti-alpha4 integrin antibody on brain lesion activity in MS. The UK Antegren Study Group. Neurology 53(3): 466-472

36. Bayless KJ, Meininger GA, Scholtz JM, Davis GE (1998) Osteopontin is a ligand for the alpha4beta1 integrin. J Cell Sci 111(Pt 9): $1165-1174$

37. Lobb RR, Hemler ME (1994) The pathophysiologic role of alpha 4 integrins in vivo. J Clin Invest 94(5):1722-1728

38. Tchilian EZ, Owen JJ, Jenkinson EJ (1997) Anti-alpha 4 integrin antibody induces apoptosis in murine thymocytes and staphylococcal enterotoxin B-activated lymph node $\mathrm{T}$ cells. Immunology 92(3):321-327 